Saudi Journal of Medical and Pharmaceutical Sciences

Abbreviated Key Title: Saudi J Med Pharm Sci ISSN 2413-4929 (Print) |ISSN 2413-4910 (Online) Scholars Middle East Publishers, Dubai, United Arab Emirates Journal homepage: https://saudijournals.com/sjmps

\title{
Giant Pleomorphic Adenoma of the Palate
}

Touiheme N*, Hmidi M, Nakkabi I, Belatik H, Attifi H, Nadour K, Boukhari A

ENT and head and neck surgery, Military Hospital Moulay Ismail Meknes Military Hospital My Ismaïl BP: S 15 Meknes- Morocco

DOI: $10.36348 /$ sjmps.2020.v06i02.012 $\quad$ | Received: 05.02.2020 | Accepted: 13.02.2020 | Published: 26.02 .2020

*Corresponding author: Touiheme Nabil

\section{Abstract}

Pleomorphic adenoma is a benign tumor, the most common of the main salivary glands, especially in the parotid gland, its location at the palate is quite rare is quite rare. The aim of our work is to report a clinical case of a 60 year old patient who had a giant pleomorphic adenoma, and analyze the clinical, paraclinical and therapeutic aspects of this tumor.

Keyswords: Pleomorphic adenoma - Palate - surgery.

Copyright @ 2020: This is an open-access article distributed under the terms of the Creative Commons Attribution license which permits unrestricted use, distribution, and reproduction in any medium for non-commercial use (NonCommercial, or CC-BY-NC) provided the original author and source are credited.

\section{INTRODUCTION}

Salivary gland tumors constitute about $3 \%$ of all neoplasms. The majority of these tumors are benign, of which about $70 \%$ are pleomorphic adenomas. It most often concerns the main salivary glands. The palate, nasal cavity, and nasopharynx have abundant minor salivary glands, and PA is the most common benign tumor of these glands. The palate is the most common site of the minor salivary glands affected $[1,2]$.

\section{Case Report}

A 60 old-year female, with no notable pathological history, who has been presenting for more than 10 years, swelling of the bony palate slowly and gradually increasing in volume, becoming bothersome with speech and chewing what motivated the consultation in our service.

Physical examination revealed a solitary well-defined dome- shaped growth on the palate, Lateralised on the left, extending back to the soft palate, below in contact with the dorsal surface of the tongue, in front and outside in contact with the left incisors, measuring $4 \mathrm{~cm} \times 3 \mathrm{~cm}$ in size with smooth surface [Figure 1]. Lymph node examination did not find cervical lymphadenopathy.

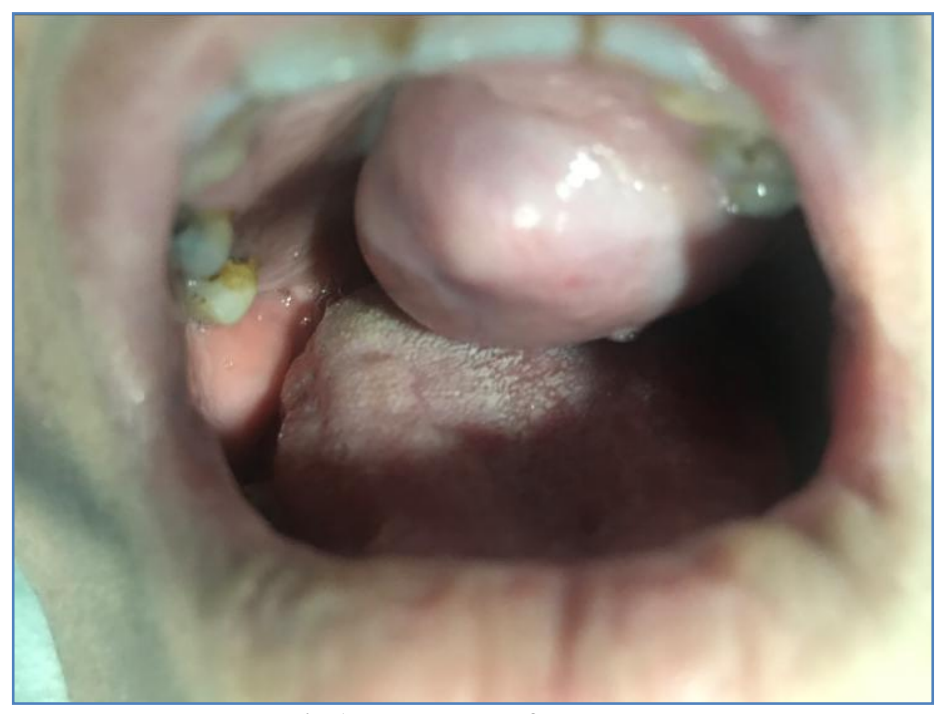

Fig-1: large tumor of the palate 
Computed tomography (CT) scan underwent an osteolytic lesion process of the bony palate lateral to the left, heterogeneous, of moderate enhancement, measuring 40/35/39 $\mathrm{mm}$. (figure 2).

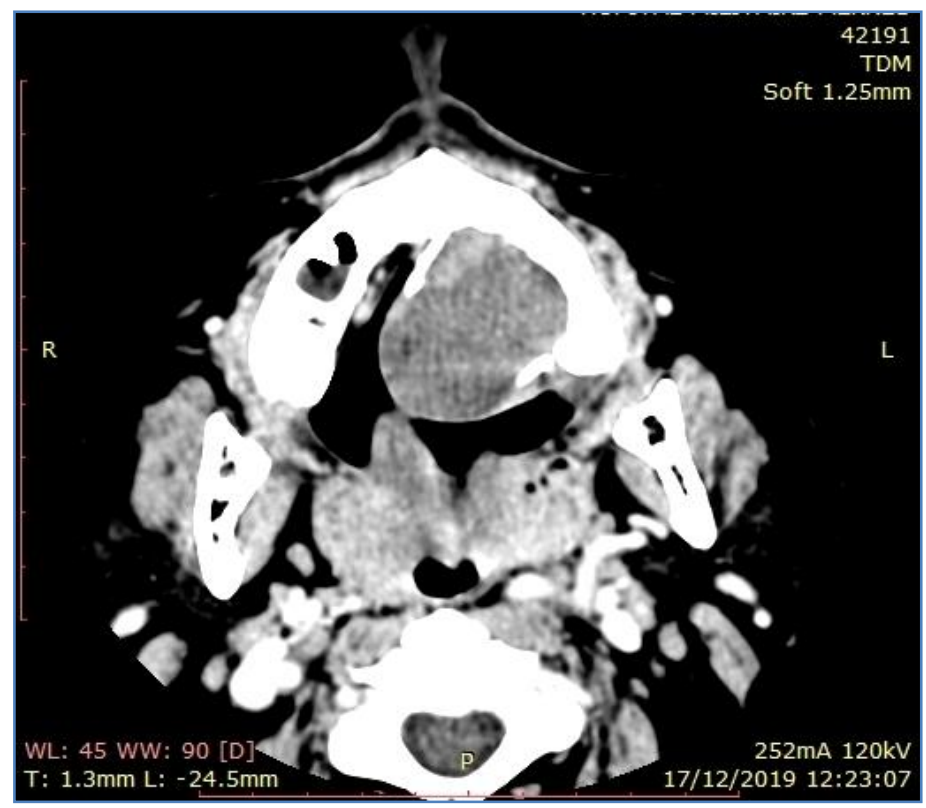

Fig-2: Axial computed tomography scan showing the extent of tumor

Fine needle aspiration cytology was performed. Histology has been in favor of a benign salivary tumor without specifying the exact nature.
Based on physical examination, Aspiration cytology and CT results, surgical treatment was scheduled after the patient's consent, and consists of a surgical excision under general anesthesia by the intraoral approach (figure 3).

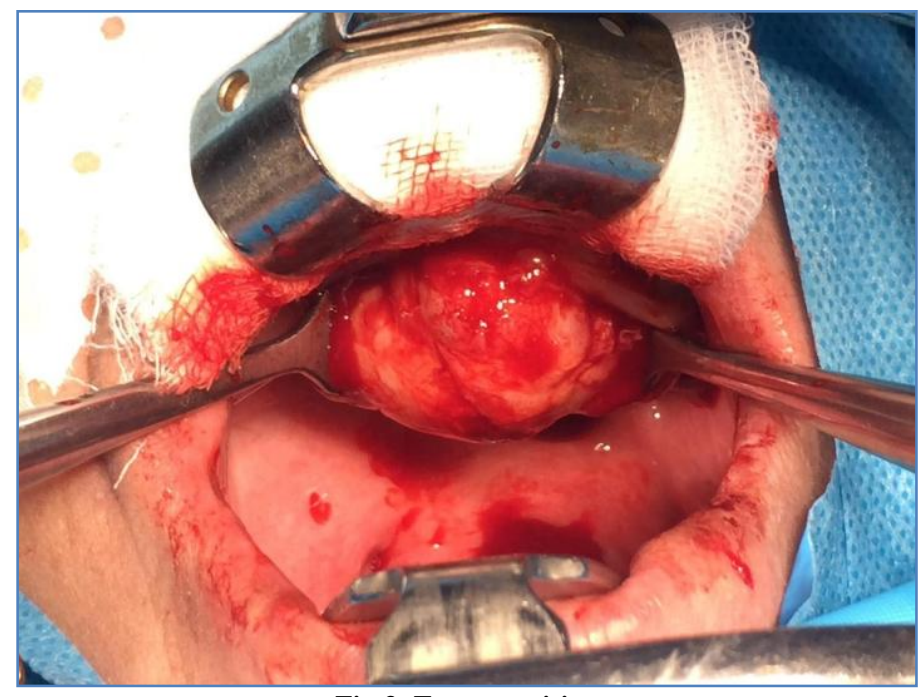

Fig-3: Tumor excision

An longitudinal incision was made, dissection of the contours of the tumor with sufficient clinical margins and total excision, closing of the mucosa was possible without tension.

The excised tumor was addressed for the histopathological study and the result was in favor of a pleomorphic adenoma. The immediate post-operative follow-up was simple; there was no recurrence after 1 year of follow- up.

\section{DiscUSSION}

Pleomorphic adenoma of the accessory salivary glands accounts for $60 \%$ of oral salivary tumors [3]. Its preferred location is the palate, due to the richness of its submucosa in accessory salivary glands, followed by the lip, cheek and oropharynx [4]. At the level of the palate, this tumor most often involves the lateral part; the midline and the veil are exceptionally affected. 
It appears in subjects at any age with a greater frequency between the ages of 30 and 60 years old and can be found equally in both sexes [5].

Histologically, this tumor is generally round and well-defined. Since it is often surrounded with a discontinuous fibrous capsule, the recurrence is possible if the removal was not sufficiently performed. Its structure is polymorphic. It is composed of epithelial and myoepithelial cells and various mesenchymal substances [TGSA].

Clinically, it's usually a small submucosal tumor, painless, bumpy and covered with normal mucosa without peritumoral inflammation [2, 3]. Growth is slow in most cases and this fact over several years.

The giant forms are responsible for an obstructive syndrome of the upper aerodigestive tract with swallowing discomfort, dyspnea, snoring and slurred speech $[2,5,6]$.

CT scan and Magnetic resonance imaging $(M R I)$ are the important diagnostic tools of these tumors; its help to determine the extension of the lesion $[2,7]$. Cytological findings in PA are typical of mixed epithelial cells and mesenchymal elements.

Despite its slow growth, a pleomorphic adenoma must be rapidly and radically treated because it can unpredictably evolve into a carcinoma. Certain signs may sometimes alert the practitioner such as an appearance of ulceration, a sudden increase of the tumor volume or a presence of satellite adenopathy of suspicious character [5].

Surgical excision is the treatment of choice. The primary goal of excision should be complete excision of the tumor with at least $1 \mathrm{~cm}$ clinical margin to avoid any chances of recurrence [7]. This complete excision is made difficult, when it comes to large tumors, by the absence of capsule and infiltration of the accessory salivary glands between muscle fibers and fat pannicles. It may require the use of reconstruction flaps in case of significant mucosal excision.

Longevity and recurrence are risk factors for malignant transformation. The propensity for malignant transformation is documented to be $1.9 \%-23.3 \%$.In spite of a long duration (30 years) [2, 7].

\section{CONCLUSION}

Giant pleomorphic adenoma of the palate is rare and can cause therapeutic difficulties. His prognosis is generally good, but remains marked by a high risk of recurrence after surgery and carcinomatous degeneration, requiring early surgical management and long-term monitoring.

\section{REFERENCES}

1. Chaturvedi, M., Jaidev, A., Thaddanee, R., \& Khilnani, A. K. (2018). Large pleomorphic adenoma of hard palate. Annals of maxillofacial surgery, 8(1), 124.

2. Aljalil, A., Touati, M., Chihani, M., Bouaity, B., \& Ammar, H. (2011). Volumineux adénome pléomorphe du palais: particularités histologiques et thérapeutiques.

3. Gleizal, A., Merrot, O., \& Bouletreau, P. (2005). Affections vélopalatines. EMC-Stomatologie, 1(2), 141-161.

4. El, A. K., Essakalli, L., Kzadri, M., Sefiani, S., \& Seffar, Z. A. (2007). Pleomorphic adenoma of the tongue base. Revue de stomatologie et de chirurgie maxillo-faciale, 108(3), 215-217.

5. Gauzeran, D. (2011). Pathologies tumorales des glandes salivaires accessoires. Revue d'OdontoStomatologie, 54.

6. Nouri, H., Raji, A., Elhattab, Y., Rochdi, Y., \& M'barek, B. A. Adénome pléomorphe de la voûte palatine. À propos d'un cas.

7. Chaturvedi, M., Jaidev, A., Thaddanee, R., \& Khilnani, A. K. (2018). Large pleomorphic adenoma of hard palate. Annals of maxillofacial surgery, $8(1), 124$. 